\title{
Desenvolvimento do milho sob influência de árvores de pau-branco em sistema agrossilvipastoril
}

\author{
Marlete Moreira de Sousa Mendes ${ }^{(1)}$, Claudivan Feitosa de Lacerda( ${ }^{(2)}$, Ana Clara Rodrigues Cavalcante ${ }^{(3)}$, \\ Francisco Éden Paiva Fernandes ${ }^{(3)}$ e Teógenes Senna de Oliveira(4)
}

\begin{abstract}
(1)Universidade Federal do Ceará (UFC), Campus do Pici, Bloco 807, CEP 60455-760 Fortaleza, CE. E-mail: mendes758@hotmail.com (2)UFC, Departamento de Engenharia Agrícola, Bloco 804. E-mail: cfeitosa@ufc.br ${ }^{(3)}$ Embrapa Caprinos e Ovinos, Estrada Sobral/Groaíras, Km 4, CEP 62010-970 Sobral, CE. E-mail: ana.clara@embrapa.br, eden.fernandes@embrapa.br (4)Universidade Federal de Viçosa, Centro de Ciências Agrárias, Departamento de Solos, CEP 36570-000 Viçosa, MG. E-mail: teo@ufv.br
\end{abstract}

Resumo - O objetivo deste trabalho foi avaliar o efeito das árvores de pau-branco (Cordia oncocalyx) sobre parâmetros fisiológicos, altura e biomassa do milho, em diferentes distâncias das árvores, em sistema agrossilvipastoril. Utilizou-se o delineamento experimental de blocos ao acaso, com quatro tratamentos (distâncias do caule das árvores de 1, 2, 3 e 4 m), além do controle (plantas do cultivo tradicional), e cinco repetições. Cada parcela consistiu de uma árvore de pau-branco, ao centro, e linhas de milho plantadas nas quatro distâncias avaliadas do caule. As medidas fisiológicas e a produção de matéria seca foram registradas aos 30,60 e 90 dias após o semeio do milho. As plantas sob a copa do pau-branco, a 1 e 2 m do caule, tiveram suas trocas gasosas, altura e produção de matéria seca afetadas pelas árvores. As plantas cultivadas a $3 \mathrm{~m}$ do caule tiveram desempenho semelhante ao observado no cultivo tradicional, e as cultivadas a $4 \mathrm{~m}$ apresentaram maior fotossíntese, condutância estomática, transpiração, altura e produção de matéria seca. As plantas de milho sob a copa são afetadas negativamente pelo sombreamento das árvores, enquanto as plantas fora da copa podem se beneficiar da presença das árvores no sistema.

Termos para indexação: Cordia oncocalyx, Zea mays, agrossilvicultura, cultivo consorciado, integração lavoura-pecuária-floresta, sistemas agroflorestais.

\section{Development of maize under influence of "pau-branco" trees in an agrosilvopastoral system}

\begin{abstract}
The objective of this work was to evaluate the effect of "pau-branco" (Cordia oncocalyx) trees on physiological parameters, height, and biomass of maize at different distances from the trees in an agrosilvipastoral system. The experimental design was a randomized complete block with four treatments (distances from trees of 1, 2,3 , and $4 \mathrm{~m}$ ), besides a control (plants cultivated in the traditional system), and five replicates. The plots consisted of one "pau-branco" tree at the center, and maize rows planted at the four evaluated distances from the tree stem. Physiological measurements and dry matter production were recorded at 30,60, and 90 days after the sowing of maize. The plants under the canopy of "pau-branco" - at 1 and $2 \mathrm{~m}$ from the stem - had their gas exchange, height, and dry matter production affected by the trees. The plants $3 \mathrm{~m}$ away from the stem had similar performance to those in the traditional system, and the plants at $4 \mathrm{~m}$ of distance had higher photosynthesis, stomatal conductance, transpiration, height, and dry mass production. Maize plants under the canopy are negatively affected by tree shading, whereas plants outside the canopy can be favored by the presence of trees in the system.
\end{abstract}

Index terms: Cordia oncocalyx, Zea mays, agri-silviculture, intercropped cultivation, crop-livestock-forest integration, agroforestry systems.

\section{Introdução}

Sistemas agroflorestais são caracterizados pelo cultivo de diferentes espécies de plantas perenes, arbóreas ou herbáceas, em associação com culturas agrícolas (silviagrícolas), com animais (silvipastoris) ou com ambos (agrossilvipastoris). Esses sistemas representam uma forma de uso potencialmente mais sustentável da terra, em razão, principalmente, da diversificação da exploração agrícola e florestal promovida (Balbino et al., 2011). Em sistemas agroflorestais, busca-se a otimização das interações biológicas entre árvores e os cultivos agrícolas ou de animais (Molua, 2005). Tais sistemas também são eficientes na redução dos efeitos da erosão hídrica e capazes de manter elevados os teores de carbono orgânico, em comparação a outras práticas agrícolas, 
comumente adotadas em região semiárida (Maia et al., 2007; Aguiar et al., 2010).

Os componentes arbóreos das agroflorestas podem aumentar, consideravelmente, o consumo de água das chuvas, em comparação aos cultivos anuais (Lott et al., 2003), mas também promovem maior retenção de água em subsuperfície, no solo (Wang et al., 2011), e aumentam o potencial de sequestro de carbono (Albrecht \& Kandji, 2003). As árvores podem contribuir para melhoria local das condições de cultivo e desenvolvimento de outras espécies, o que influencia a produtividade do sistema (Yang et al., 2009) e pode aumentar a rentabilidade do empreendimento consorciado, em comparação ao monocultivo (Ogol etal., 1999). Para que isso ocorra, no entanto, énecessário que as árvores não compitam de forma excessiva com a cultura agrícola (Mathuva et al., 1998). Dessa forma, em ambientes onde o fator limitante é o baixo teor de nutrientes no solo, a introdução de árvores com folhas com alto teor de nutrientes e de decomposição rápida, como Gliricidia spp. e Leucaena spp. (Heineman et al., 1997), pode aumentar a produtividade do sistema. Se houver escassez de água, é possível que as árvores mantenham maior umidade próximo a elas, quer seja por meio do escoamento pelo tronco (Jackson et al., 2000) ou pela extração de água de solo profundo, via redistribuição hidráulica (Sekiya \& Yano, 2002).

A escolha das espécies arbóreas para integrarem o cultivo consorciado, em sistema agroflorestal, deve considerar sua eficiência no uso da água, já que árvores com essa característica são menos competitivas com o cultivo (Radersma \& Ong, 2004). Outro aspecto importante é a profundidade de alcance do sistema radicular, pois se ele for profundo, há possibilidade de absorção de água e nutrientes em locais onde os cultivos agrícolas não exploram (Jackson et al., 1995). Caso o componente arbóreo apresente sistema radicular superficial, a área sob as árvores, além de sombreadas, apresentarão baixa disponibilidade de água (Schroth et al., 2002). Dessa forma, as agroflorestas podem influenciar de forma positiva ou negativa os cultivos agrícolas, dependendo das características morfológicas e fisiológicas das espécies associadas. Bertomeu (2012) observou queda de 19 a 66\% na produção de biomassa aérea e no rendimento do grãos do milho em sistema agroflorestal, de acordo com o espaçamento entre as árvores.
Pesquisas sobre o rendimento do milho, em sistema agroflorestal, são comuns (Mathuva et al., 1998; Pérez-Marin et al., 2006; Bertomeu, 2012), mas poucas abordam aspectos fisiológicos, sobretudo em região semiárida, como o Nordeste brasileiro. Ding \& Su (2010) observaram, em região com precipitação pluvial anual acima de $2.000 \mathrm{~mm}$, efeito da presença de árvores sobre a transpiração do milho, o que causou variações no rendimento do cultivo. Kang et al. (2008), ao avaliar o efeito da poda das árvores sobre parâmetros fisiológicos do milho, concluíram que essa prática aumenta a incidência de radiação fotossinteticamente ativa e permite maior transpiração da cultura, o que melhora sua capacidade de competição por água e luz. De acordo com os autores, as plantas mais distantes das árvores são menos afetadas.

A produtividade média do milho, variedade Catingueiro, obtida em ensaios conduzidos na região semiárida brasileira em condições de sequeiro, entre 1998 e 2003, foi de 2 a $3 \mathrm{Mg} \mathrm{ha}^{-1}$ (Carvalho et al., 2004). Em 2011, a produtividade desta variedade em sistema agrossilvipastoril foi de $1.687 \mathrm{~kg} \mathrm{ha}^{-1}$, enquanto em monocultivo foi de $897,5 \mathrm{~kg} \mathrm{ha}^{-1}$, ambas são superiores às médias para a região de Sobral $\left(790,0 \mathrm{~kg} \mathrm{ha}^{-1}\right.$, entre 1999 e 2011) e para o Estado do Ceará (714,0 $\mathrm{kg} \mathrm{ha}^{-1}$, entre 1997-2008) (Companhia Nacional de Abastecimento, 2012). A produtividade, para o mesmo ano (2011), no Município de Sobral foi de $1.313 \mathrm{~kg} \mathrm{ha}^{-1}$ e a do Estado foi de $1.394 \mathrm{~kg} \mathrm{ha}^{-1}$ (Companhia Nacional de Abastecimento, 2013).

O objetivo deste trabalho foi avaliar o efeito de árvores de pau-branco (Cordia oncocalyx Allemão) sobre parâmetros fisiológicos, altura e biomassa do milho, em diferentes distâncias das árvores, em sistema agrossilvipastoril.

\section{Material e Métodos}

O experimento foi realizado na Fazenda Crioula, pertencente à Embrapa Caprinos e Ovinos, situada no Município de Sobral, CE ( $3^{\circ} 41^{\prime} \mathrm{S}$ e $\left.40^{\circ} 20^{\prime} \mathrm{W}\right)$. O clima da região é do tipo $\mathrm{BSw}$ 'h', segundo a classificação de Köppen, com estação chuvosa de janeiro a maio. A temperatura e a precipitação médias anuais são de $30^{\circ} \mathrm{C}$ e $821,6 \mathrm{~mm}$, respectivamente. Os solos da área experimental apresentam manchas de Luvissolo Crômico órtico típico e Luvissolo Hipocrômico órtico típico (Aguiar et al., 2006).

Pesq. agropec. bras., Brasília, v.48, n.10, p.1342-1350, out. 2013 DOI: 10.1590/S0100-204X2013001000005 
$\mathrm{O}$ experimento foi realizado em duas áreas experimentais: sistema agrossilvipastoril (AGP) e área de cultivo tradicional (TR). O sistema agrossilvipastoril foi implantado em 1997, em 1,7 ha, com cultivo em aleias. Esse sistema consiste de, aproximadamente, 200 árvores nativas por hectare, o que corresponde a $22 \%$ de cobertura do solo. O sistema tradicional consiste de área com 1,3 ha de cultivo de milho em monocultura, preparada com retirada da vegetação e queima dos resíduos (manejo tradicional na região). Não houve adição de fertilizantes ou uso de irrigação em nenhum dos sistemas. Após a colheita do milho, os animais (caprinos e ovinos) tiveram acesso à área para se alimentar.

Entre as espécies arbóreas presentes no sistema, o pau-branco (Cordia oncocalyx Allemão, Boraginaceae) foi escolhido por ser comum na área, com frequência, dominância e densidade relativas de 36,84, 79,03 e $58,33 \%$, respectivamente (Campanha et al., 2011). Essa espécie é caducifólia e endêmica da Caatinga. Suas folhas são simples, alternas, oblongas e medem de 12 a $35 \mathrm{~cm}$ de comprimento por 4 a $12 \mathrm{~cm}$ de largura. Foram selecionados cinco espécimes, pela similaridade de diâmetro à altura do peito (aproximadamente $30 \mathrm{~cm}$ ), com altura média de $9 \mathrm{~m}$. O surgimento das folhas e a floração acontecem logo no início do período chuvoso (janeiro/fevereiro), a frutificação inicia-se em seguida (março), e os frutos perduram até o início da estação seca (julho/agosto).

O milho (Zea mays L.) variedade Catingueiro, foi avaliado em condições de monocultivo e em integração no sistema agrossilvipastoril. Para averiguar o efeito das árvores sobre o cultivo, foram delimitadas cinco áreas (uma para cada tratamento), com 8x8 m. Nas áreas do sistema integrado, havia um exemplar do pau-branco ao centro e quatro linhas de milho, a $1 \mathrm{~m}$ de distância entre si, em cada lado da árvore, no sentido norte-sul. Foram semeadas três sementes de milho por cova, com espaçamento de $1 \mathrm{~m}$ entre as covas e entre as linhas. O milho foi semeado entre 15 e 16 de fevereiro de 2011 e colhido em 17 e 18 de maio. A precipitação foi de 185, 193,3, 155,2 e 165,6 mm, em fevereiro, março, abril e maio, respectivamente. No TR, o milho foi plantado com distâncias de $1 \mathrm{~m}$ entre linhas e 0,5 m entre covas; e no AGP, o espaçamento foi de 1x1 $\mathrm{m}$, conforme Moura et al. (2008) em experimento com milho consorciado.
Foram avaliadas quatro distâncias das linhas de plantio do milho, a partir do caule do pau-branco: 1 , 2, 3, e $4 \mathrm{~m}$. Nas duas primeiras distâncias, o milho ficou completamente sob a copa; a terceira distância era intermediária; e, na quarta, as plantas estavam completamente expostas ao sol (fora da copa), tendo-se considerado a projeção da copa ao meio-dia.

As médias históricas mensais (1974-2011) de precipitação para o Município de Sobral, CE, foi de $103,7 \pm 85,7 ; 153,4 \pm 82,9 ; 230,0 \pm 129,2 ; 221,0 \pm 106,8$ e $121,6 \pm 79,6 \mathrm{~mm}$, respectivamente para os meses de janeiro a maio, enquanto as normais históricas (19611990) de temperaturas médias foram de 26,7, 27,1, $26,2,27,5$ e $26,2^{\circ} \mathrm{C}$, para os referidos meses. No ano de 2011, a precipitação mensal foi de 159,1, 185,0, 193,3, 155,2 e 165,6 mm para janeiro, fevereiro, março, abril e maio, respectivamente, enquanto os valores de temperatura média foram $25,1,25,0,24,7$ e $25,2^{\circ} \mathrm{C}$ para fevereiro, março, abril e maio, respectivamente.

As coletas e os registros de dados foram realizados aos 30, 60 e 90 dias após o semeio (DAS), que coincidiu com os meses de março, abril e maio, e com as fases vegetativa, reprodutiva e senil, respectivamente. Para tanto, foi utilizada, mensalmente, uma linha de milho, no sentido leste-oeste. Cada linha continha uma planta por tratamento, em cada parcela, o que totalizou cinco plantas por tratamento. Para coleta no TR, foi selecionada, aleatoriamente, uma linha por mês, no sentido leste-oeste, e, a cada cinco plantas, uma era coletada, até obter-se o total de cinco espécimes.

Aos 30 e 60 DAS, foram registrados dados de radiação fotossinteticamente ativa (RFA), razão entre concentração de $\mathrm{CO}_{2}$ interna à folha e do ar $\left(\mathrm{C}_{\mathrm{i}} / \mathrm{C}_{\mathrm{ar}}\right)$, temperaturas do ar $\left(\mathrm{T}_{\mathrm{ar}}\right)$ e foliar $\left(\mathrm{T}_{\mathrm{fol}}\right)$, fotossíntese líquida (A), condutância estomática (gs) e transpiração (E), com uso de analisador de gás infravermelho LI-6400 (LI-COR, Lincoln, NE, EUA), tendo-se utilizado a primeira folha apical completamente expandida, uma folha por planta e cinco plantas por tratamento, das 12 às $13 \mathrm{~h}$. As concentrações de clorofila, no limbo foliar, foram medidas por meio de medidor portátil SPAD-502, (Minolta, Osaka, Japão), e os resultados foram representados por meio do índice de conteúdo de clorofila SPAD. Cabe ressaltar que, em maio, não foi possível realizar essas medidas porque as folhas de milho já estavam secas.

O potencial hídrico ( $\Psi$ ) foi medido aos 60 DAS, ao meio-dia, com uso de câmara de pressão de Scholander 
(Soil Moisture Equipment Corp., Goleta, CA, EUA). Foram utilizadas as mesmas folhas das leituras de clorofila e de trocas gasosas, em cinco exemplares de milho, para cada tratamento.

Antes da coleta da parte aérea, aos 30, 60 e 90 DAS, a altura das plantas foi medida do colo ao ápice da última folha completamente expandida (30 DAS) ou das inflorescências (60 e 90 DAS). Aos 90 DAS, além da parte aérea, as espigas também foram colhidas. Foram obtidas as massas de matéria fresca e seca, em estufa com circulação de ar a $65^{\circ} \mathrm{C}$, até peso constante. O material foi pesado novamente para obtenção da massa de matéria seca da parte aérea (colmo, folhas e inflorescências) e da espiga (palha, sabugo e grãos).

Utilizou-se o delineamento experimental de blocos ao acaso, com cinco repetições, com quatro tratamentos representados pelas distâncias de cultivo, além da testemunha, com cultivo tradicional do milho. Os dados foram submetidos à análise de variância, e as médias foram comparadas pelo teste de Tukey, a $5 \mathrm{e}$ $1 \%$ de probabilidade.

\section{Resultados e Discussão}

A distância das árvores não afetou a temperatura do ar ou da folha de milho, medida nos horários de leitura das trocas gasosas (12 às 13h), aos 30 DAS (Tabela 1). Entretanto, aos 60 DAS, a temperatura do ar no sistema de cultivo tradicional foi menor que a no sistema integrado. Esse resultado não é comumente relatado na literatura, quando se comparam áreas com diferentes coberturas. De acordo com Lemenih et al. (2004), quanto maior o percentual de fechamento do dossel e o índice de área foliar, menor a temperatura do ar. Souza et al. (2012) verificaram aumento, em até 6 graus, na temperatura do ar onde havia cultivo de café a pleno sol, em comparação a áreas de sistema agroflorestal ou floresta. Pérez-Marin et al. (2006) constataram menores valores de temperatura do ar sob as árvores de Gliricidia sepium, em sistema agroflorestal, com cultivo de milho, do que a $3 \mathrm{~m}$ de distância, durante a época chuvosa e ao fim dela.

Aos 60 DAS, foi observada menor temperatura foliar nas plantas dos tratamentos de 1 a $3 \mathrm{~m}$ de distância das árvores, quando comparado à observada à $4 \mathrm{~m}$ (Tabela 1); no entanto, nas distâncias de $1 \mathrm{a}$ $3 \mathrm{~m}$, não houve diferença na temperatura do ar entre os tratamentos. Esses resultados são indicativos de um melhor suprimento de água para as plantas de milho próximas às árvores de pau-branco, pois em situações de suprimento de água e radiação adequadas, plantas adaptadas ao sol pleno, como o milho, mantêm seus processos fisiológicos, com abertura normal de seus estômatos, para absorção de $\mathrm{CO}_{2}$ e dissipação de energia na forma de calor. Em condições menos favoráveis de suprimento de água ou radiação, a tendência é que os estômatos sejam fechados, o que aumenta a temperatura no interior da folha. Temperaturas do ar abaixo de $15^{\circ} \mathrm{C}$ (Foyer et al., 2002) ou acima de $38^{\circ} \mathrm{C}$ podem diminuir a biomassa das plantas de milho, que têm seu melhor desenvolvimento fotossintético entre 32 e $34^{\circ} \mathrm{C}$ ( $\mathrm{Kim}$ et al., 2007). Essa faixa está próxima da registrada em ambos os sistemas de cultivo, neste trabalho, o que indica que a temperatura do ar esteve diretamente relacionada às diferenças no desenvolvimento do milho, nesses sistemas.

A radiação que chegou às plantas de milho aos 30 e 60 DAS foi maior nos tratamentos a 3 e $4 \mathrm{~m}$, e no cultivo tradicional (Figura 1). Kang et al. (2008), ao estudar o efeito das árvores no desenvolvimento do milho, em sistema agroflorestal, notaram reduções na radiação fotossinteticamente ativa quando as plantas estavam mais próximas das árvores, especialmente aos 60 DAS, o que, segundo os autores, acarretou queda no rendimento do milho. Com a diminuição da taxa de radiação, a absorção de fótons é diminuída, o transporte eletrônico é afetado e a etapa fotoquímica, bem como a fotossíntese, é alterada.

Aos 30 DAS, nos tratamentos a 1 e $4 \mathrm{~m}$, a fotossíntese do milho foi de 6,6 e $27,3 \mu \mathrm{mol} \mathrm{m} \mathrm{m}^{-2} \mathrm{~s}^{-1}$, sob RFA de

Tabela 1. Temperatura do ar e das folhas de milho, medida ao meio dia, aos 30 e 60 dias após o semeio (DAS), em sistema agrossilvipastoril, às distâncias de $1,2,3$ e $4 \mathrm{~m}$ do caule de pau-branco (Cordia oncocalyx), em comparação ao sistema de cultivo tradicional.

\begin{tabular}{lccccc}
\hline Tratamento & \multicolumn{2}{c}{30 DAS } & & \multicolumn{2}{c}{60 DAS } \\
\cline { 2 - 3 } \cline { 5 - 6 } & $\operatorname{Ar}$ & Folha & & $\operatorname{Ar}$ & Folha \\
\hline Cultivo tradicional & 34,04 & 31,48 & & 33,04 & 33,03 \\
Distância 1 m & $34,91^{\mathrm{ns}}$ & $31,34^{\mathrm{ns}}$ & & $35,34^{* *}$ & $32,57^{\mathrm{ns}}$ \\
Distância 2 m & $34,83^{\mathrm{ns}}$ & $31,20^{\mathrm{ns}}$ & & $35,33^{* *}$ & $32,98^{\mathrm{ns}}$ \\
Distância 3 m & $34,76^{\mathrm{ns}}$ & $31,10^{\mathrm{ns}}$ & & $35,36^{* *}$ & $33,92^{\mathrm{ns}}$ \\
Distância 4 m & $34,73^{\mathrm{ns}}$ & $32,02^{\mathrm{ns}}$ & & $35,33^{* *}$ & $34,44^{*}$ \\
\hline
\end{tabular}

ns Não significativo. * e **Significativo pelo teste de Tukey, a 5 e $1 \%$ de probabilidade, respectivamente. 
244,3 e $714 \mu \mathrm{mol} \mathrm{m} \mathrm{m}^{-2} \mathrm{~s}^{-1}$, respectivamente. Aos 60 DAS, esses valores foram de 2,29 e 41,83 $\mu \mathrm{mol} \mathrm{m}^{-2} \mathrm{~s}^{-1}$, sob RFA de 97,1 e 1.839,6. Plantas $\mathrm{C}_{4}$ apresentam alta capacidade fotossintética ( $55 \mu \mathrm{mol} \mathrm{m} \mathrm{m}^{-2} \mathrm{~s}^{-1}$ ou mais); o milho, por exemplo, não apresenta fotossíntese líquida saturada mesmo sob forte radiação (Larcher, 2006). Kim et al. (2007) verificaram os maiores valores de fotossíntese (aproximadamente $40 \mu \mathrm{mol} \mathrm{m} \mathrm{m}^{-2} \mathrm{~s}^{-1}$ ) com
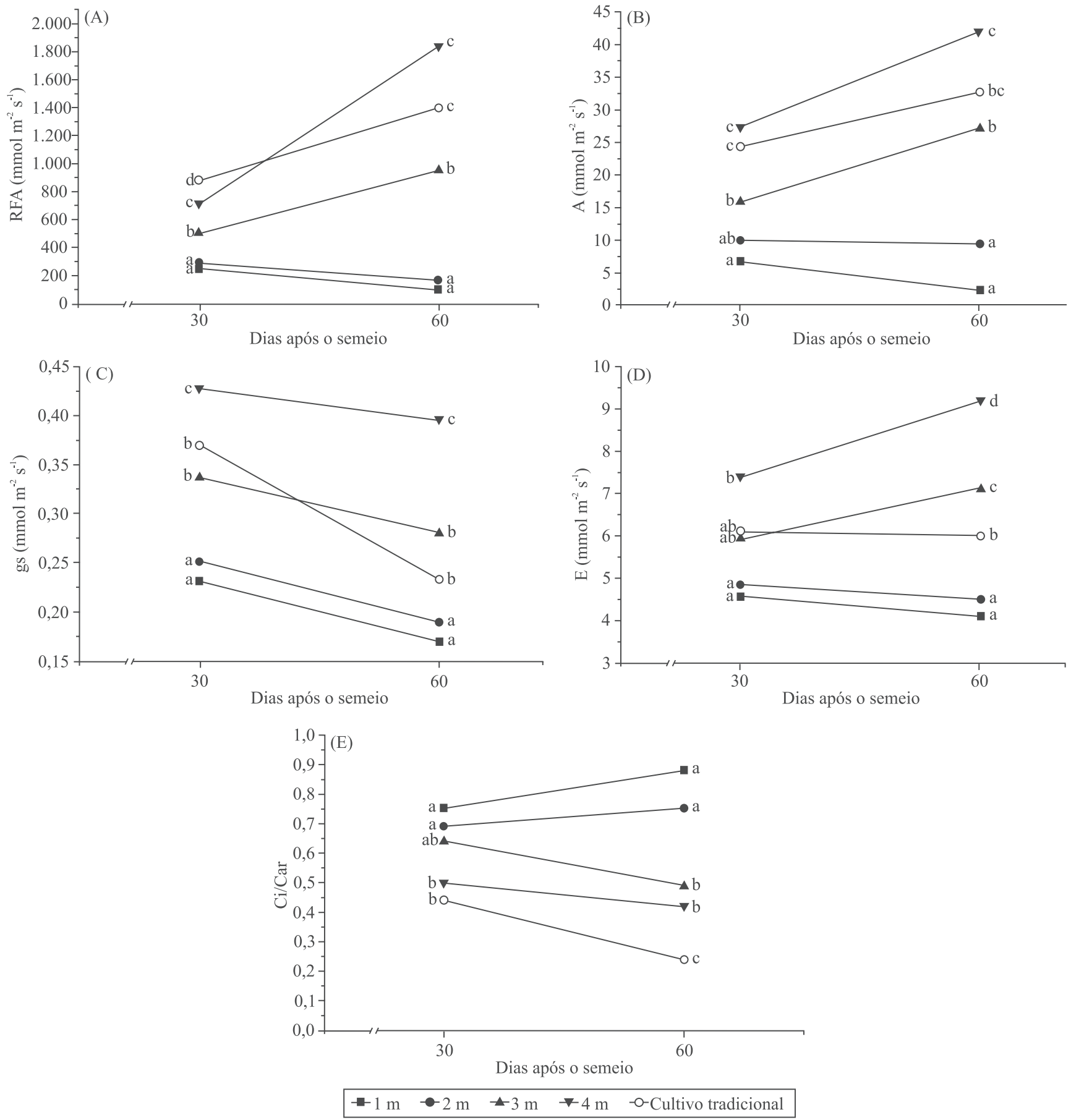

Figura 1. Parâmetros fisiológicos de plantas de milho cultivadas em sistema agrossilvipastoril, a distâncias de 1, 2, 3 e $4 \mathrm{~m}$ do caule de pau-branco (Cordia oncocalyx), e em sistema de cultivo tradicional, aos 30 e 60 dias após o semeio: A, radiação fotossinteticamente ativa (RFA); B, fotossíntese (A); C, condutância (gs); D, transpiração (E); E, razão entre concentração interna e externa de $\mathrm{CO}_{2}(\mathrm{Ci} / \mathrm{Car})$. Médias seguidas de letras iguais não diferem, entre si, pelo teste de Tukey, a 5\% de probabilidade. 
temperaturas entre 30 e $35^{\circ} \mathrm{C}$. Como no presente trabalho a temperatura do ar registrada nos horários de leitura de fotossíntese esteve nessa faixa, o baixo valor de fotossíntese observado no milho sob a copa não pode ser atribuído à temperatura. Apenas as plantas mais distantes do caule apresentaram fotossíntese condizente com as consideradas normais para o milho.

Houve aumento progressivo nas médias de fotossíntese à medida que se aumentou a distância do milho às árvores de pau-branco (Figura 1), o que acompanhou os resultados observados para a radiação interceptada pelas plantas. Reynolds et al. (2007), ao avaliar milho plantado a 2 e $6 \mathrm{~m}$ de distância do bordo-açucareiro (Acer saccharinum), obtiveram menor incidência de radiação fotossinteticamente ativa a $2 \mathrm{~m}\left(481 \mu \mathrm{mol} \mathrm{s} \mathrm{s}^{-1} \mathrm{~m}^{-2}\right)$ do que a $6 \mathrm{~m}$ $\left(1.420 \mu \mathrm{mol} \mathrm{s}^{-1} \mathrm{~m}^{-2}\right)$, com redução, na fotossíntese, de 26,9 para $12 \mu \mathrm{mol} \mathrm{m}^{-2} \mathrm{~s}^{-1} \mathrm{e}$, no rendimento, de 7,07 para $3,79 \mathrm{Mg} \mathrm{ha}^{-1}$, respectivamente.

Aos 30 e 60 DAS, a condutância estomática foi maior a $4 \mathrm{~m}$ de distância das árvores, e houve similaridade entre tratamentos a 1 e $2 \mathrm{~m}$ e entre a $3 \mathrm{~m}$ e o cultivo tradicional, aos 60 DAS (Figura 1). A transpiração foi maior a $4 \mathrm{~m}$ e menor nos tratamentos completamente sob a copa das árvores ( 1 e $2 \mathrm{~m}$ ), respectivamente aos 30 e 60 DAS. O tratamento a $3 \mathrm{~m}$ apresentou valores próximos aos observados no cultivo tradicional, embora diferentes. Os tratamentos 1 e $2 \mathrm{~m}$, aos 30 DAS, e todos os do sistema integrado, aos 60 DAS, apresentaram maior razão $\mathrm{Ci} / \mathrm{Car}$, quando comparados ao cultivo tradicional. Observaram-se valores elevados de transpiração e condutância apenas nas plantas fora da copa.

As plantas sob a copa mantêm seus estômatos fechados, em razão da baixa intensidade luminosa, o que promove redução na transpiração e na fixação de $\mathrm{CO}_{2}$. Quando isso acontece, há aumento da razão entre a concentração interna de $\mathrm{CO}_{2}$ e a do ar, em função da baixa radiação fotossinteticamente ativa, conforme demonstraram Fuentes \& King (1989), até que o $\mathrm{CO}_{2}$ possa ser incorporado à PEPcase (enzima aceptora do carbono na etapa bioquímica de plantas $\mathrm{C}_{4}$ ), quando será necessário abrir os estômatos para que ocorra novas captações de carbono da atmosfera. A reduzida absorção de luz também prejudica a etapa fotoquímica da fotossíntese, a cadeia de transporte de elétrons e parte da produção de energia necessária à etapa bioquímica, na qual há conversão de $\mathrm{CO}_{2} \mathrm{em}$ açúcares.

Aos 30 DAS, o teor de clorofila foi muito semelhante entre os tratamentos dos sistemas integrado e tradicional (Figura 2). Aos 60 dias, o índice SPAD, no sistema tradicional, foi bem inferior ao do milho no sistema integrado. Concentrações de clorofila estão diretamente relacionadas ao sombreamento, de forma que, quanto maior o sombreamento, maior o teor de clorofila (Rego \& Possamai, 2006). Como no presente trabalho a relação entre radiação e teor de clorofila não foi observada, é provável que outros fatores tenham atuado para diferenciar as plantas entre os dois sistemas. Entre esses fatores, está o suprimento de N, conforme constatado por Maia et al. (2008), e o estádio fisiológico, uma vez que as plantas no cultivo tradicional estavam mais próximas do início da senescência. No sistema integrado, mesmo as plantas fora da copa apresentaram elevados teores de clorofila, maiores que os das plantas no cultivo tradicional, o que indica efeito da permanência das árvores nesse sistema sobre o suprimento de nutrientes no solo.

O potencial hídrico $(\Psi)$, ao meio-dia, foi semelhante entre os tratamentos no sistema integrado, porém maiores do que os registrados no sistema tradicional (Figura 3). O solo mais exposto, no sistema tradicional, pode ter

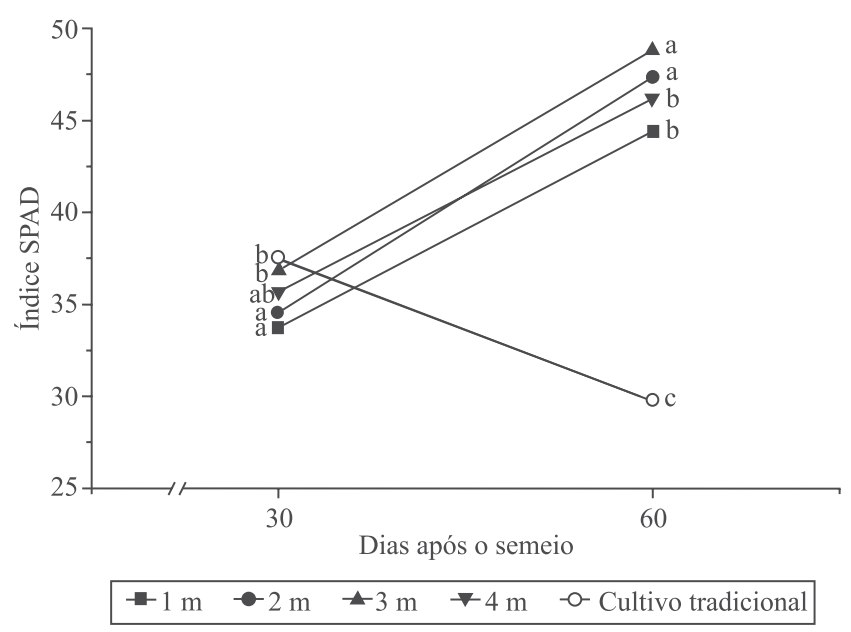

Figura 2. Teores de clorofila registrados, aos 30 e 60 dias após o semeio, em plantas de milho cultivadas em sistema agrossilvipastoril, a distâncias de 1, 2, 3 e $4 \mathrm{~m}$ do caule de pau-branco (Cordia oncocalyx), e em sistema de cultivo tradicional. Médias seguidas de letras iguais não diferem pelo teste de Tukey, a 5\% de probabilidade. 
promovido maior perda de água por evaporação, que teria se refletido em menor $\Psi$ nas plantas desse sistema. As árvores, em sistema agroflorestal, podem aumentar a disponibilidade de água e a utilização da água das chuvas para o cultivo, com melhoria nas propriedades físicas do solo, ao reduzir as perdas de água por escoamento, bem como melhorar o microclima, por meio da redução da demanda evaporativa (Lott et al., 2003).

Maiores valores de $\Psi$ revelam um melhor estado hídrico, com maior condutância estomática e transpiração (Paiva et al., 2005). Contudo, se a água no solo não for limitante às trocas gasosas, como no período chuvoso, os baixos valores de fotossíntese, transpiração e condutância dos tratamentos sob a copa, como os observados no presente trabalho, podem ser resultantes da atenuação da radiação pelas árvores de pau-branco.

As plantas de milho apresentaram maior altura à medida que se aumentou a distância de pau-branco (Tabela 1). As plantas mais altas foram encontradas no tratamento a $4 \mathrm{~m}$ de distância das árvores, que estiveram completamente fora da copa. Esse resultado pode ser atribuído ao fato de o milho ser uma espécie que não suporta sombreamento (Kho, 2000; Reynolds et al., 2007). Muthuri et al. (2005) verificaram diferença na altura do milho somente a $1 \mathrm{~m}$ de distância do caule

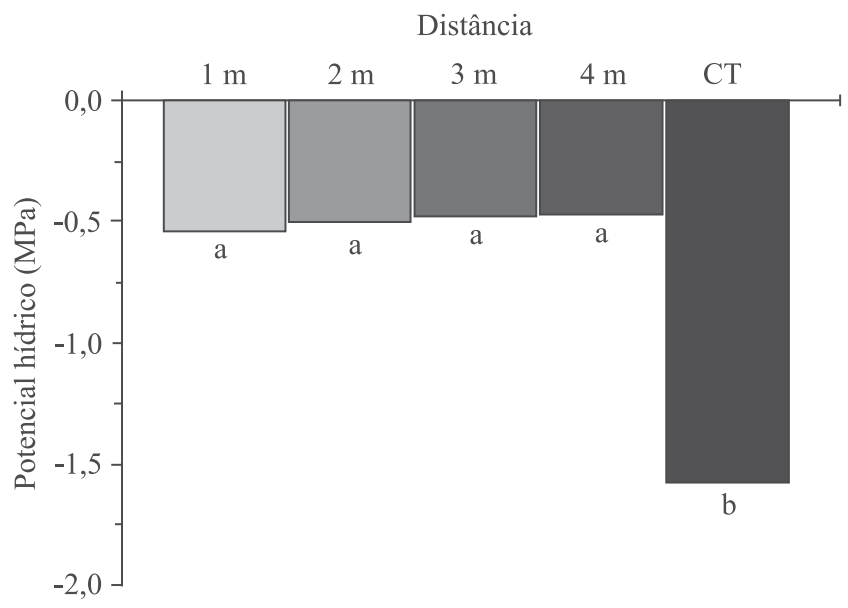

Figura 3. Potencial hídrico ao meio dia, aos 60 dias após o semeio, em plantas de milho cultivadas em sistema agrossilvipastoril, a distâncias de 1, 2, 3 e $4 \mathrm{~m}$ do caule de pau-branco (Cordia oncocalyx), e em sistema de cultivo tradicional(CT). Médias seguidas de letras iguais não diferem, entre si, pelo teste de Tukey, a 5\% de probabilidade. das árvores de Grevillea robusta, onde o milho, em sistema agroflorestal, apresentou-se menor que no cultivo isolado. As diferenças nos resultados entre os estudos podem ser atribuídas a diferenças no tamanho da copa e no índice de área foliar das espécies arbóreas utilizadas.

Os menores valores de produção de matéria seca foram observados no tratamento a $1 \mathrm{~m}$ de distância, tendo-se observado valores semelhantes entre o tratamento a $4 \mathrm{~m}$ e cultivo tradicional (Tabela 2 ). Em comparação ao cultivo tradicional, a produção de matéria seca da espiga foi menor nos tratamentos entre 1 e $3 \mathrm{~m}$ de distância das árvores, e igual no tratamento a $4 \mathrm{~m}$. Paciullo et al. (2011) também verificaram menor produção de massa de matéria seca em gramíneas forrageiras (Urochloa decumbens), em razão da proximidade das árvores em sistema agrossilvipastoril, o que foi correlacionado à menor radiação solar incidentes. Ao avaliar o efeito do sombreamento de árvores sobre o rendimento do milho, em sistema agroflorestal, Ding \& Su (2010) concluíram que a queda no rendimento das plantas sombreadas, em comparação às completamente expostas ao sol, esteve relacionada a alterações na radiação fotossinteticamente ativa incidente, à temperatura do ar e à concentração de $\mathrm{CO}_{2}$. No presente trabalho, entre os parâmetros físicos observados, a radiação, e não a temperatura do ar, influenciou a produção de matéria seca do milho.

Tabela 2. Altura e massa de matéria seca da parte aérea (MSPA) e da espiga (MSEsp) de plantas de milho, aos 30, 60 e 90 dias após o semeio (DAS), em sistema agrossilvipastoril, às distâncias de $1,2,3$ e $4 \mathrm{~m}$ do caule de pau-branco (Cordia oncocalyx), em comparação ao sistema de cultivo tradicional.

\begin{tabular}{|c|c|c|c|c|c|c|}
\hline \multirow[t]{2}{*}{ Tratamento } & \multicolumn{2}{|c|}{$30 \mathrm{DAS}$} & \multicolumn{2}{|c|}{$60 \mathrm{DAS}$} & \multicolumn{2}{|r|}{$90 \mathrm{DAS}$} \\
\hline & $\begin{array}{l}\text { Altura } \\
(\mathrm{cm})\end{array}$ & $\begin{array}{c}\text { MSPA } \\
\left(\text { g planta }^{-1}\right)\end{array}$ & $\begin{array}{c}\text { Altura } \\
(\mathrm{cm})\end{array}$ & $\begin{array}{c}\text { MSPA } \\
\left(\text { g planta }^{-1}\right)\end{array}$ & $\begin{array}{l}\text { Altura } \\
(\mathrm{cm})\end{array}$ & $\begin{array}{l}\text { MSPA MSEsp } \\
----\left(\text { g planta }^{-1}\right)---\end{array}$ \\
\hline Cultivo tradicional & 46,6 & 7,38 & 151,0 & 24,49 & 169,0 & $40,25 \quad 75,32$ \\
\hline Distância $1 \mathrm{~m}$ & $51,0^{\mathrm{ns}}$ & $3,27 * *$ & $126,0^{\mathrm{ns}}$ & $10,05 * *$ & $156,0^{\text {ns }}$ & $17,74 * * 17,92 * *$ \\
\hline Distância 2 m & $51,9^{\text {ns }}$ & $4,50 *$ & $160,4^{\mathrm{ns}}$ & $22,23^{\mathrm{ns}}$ & $171,6^{\mathrm{ns}}$ & $25,38^{\text {ns }} 26,75^{* *}$ \\
\hline Distância 3 m & $59,7 * *$ & $6,00^{\mathrm{ns}}$ & $163,4^{\mathrm{ns}}$ & $18,36^{\mathrm{ns}}$ & $177,8^{\text {ns }}$ & $21,76^{*} 26,02 * *$ \\
\hline Distância 4 m & $65,8 * *$ & $7,25^{\mathrm{ns}}$ & $190,0 * *$ & $29,61^{\text {ns }}$ & $194,0^{*}$ & $34,73^{\mathrm{ns}} 73,16^{\mathrm{ns}}$ \\
\hline
\end{tabular}




\section{Conclusão}

As plantas de milho, sob a copa de pau-branco, são afetadas negativamente pela menor radiação fotossinteticamente ativa disponível, enquanto as plantas fora da copa podem se beneficiar da presença das árvores no sistema.

\section{Agradecimentos}

À Embrapa Caprinos e Ovinos, por disponibilização das áreas experimentais; e à Coordenação de Aperfeiçoamento de Pessoal de Nível Superior, pela concessão de bolsa.

\section{Referências}

AGUIAR, M.I. de; MAIA, S.M.F.; XAVIER, F.A. da S.; MENDONÇA, E.S.; ARAÚJO FILHO, J.A.; OLIVEIRA, T.S. de. Sediment, nutrient and water losses by water erosion under agroforestry systems in the semi-arid region in northeastern Brazil. Agroforestry Systems, v.79, p.277-289, 2010. DOI: 10.1007/ s10457-010-9310-2.

AGUIAR, M.I. de; MAIA, S.M.F.; OLIVEIRA, T.S. de; MENDONÇA, E.S.; ARAUJO FILHO, J.A. Perdas de solo, água e nutrientes em sistemas agroflorestais no município de Sobral, CE. Revista Ciência Agronômica, v.37, p.270-278, 2006.

ALBRECHT, A.; KANDJI, S.T. Carbon sequestration in tropical agroforestry systems. Agriculture, Ecosystems and Environment, v.99, p.15-27, 2003. DOI: 10.1016/S0167-8809(03)00138-5.

BALBINO, L.C.; CORDEIRO, L.A.M.; PORFÍRIO-DASILVA, V.; MORAES, A. de; MARTINEZ, G.B.; ALVARENGA, R.C.; KICHEL, A.N.; FONTANELI, R.S.; SANTOS, H.P. dos; FRANCHINI, J.C.; GALERANI, P.R. Evolução tecnológica e arranjos produtivos de sistemas de integração lavoura-pecuáriafloresta no Brasil. Pesquisa Agropecuária Brasileira, v.46, p.i-xii, 2011. DOI: 10.1590/S0100-204X2011001000001.

BERTOMEU, M. Growth and yield of maize and timber trees in smallholder agroforestry systems in Claveria, northern Mindanao, Philippines. Agroforestry Systems, v.84, p.73-87, 2012. DOI: 10.1007/s10457-011-9444-x.

CAMPANHA, M.M.; ARAÚJO, F.S. de; MENEZES, M.O.T. de; SILVA, V.M.A.; MEDEIROS, H.R. de. Estrututura da comunidade vegetal arbóreo-arbustiva de um sistema agrossilvipastoril, em Sobral - CE. Revista Caatinga, v.24, p.94-101, 2011.

CARVALHO, H.W.L. de; SANTOS, M.X. dos; SILVA, A.A.G. da; CARDOSO, M.J.; SANTOS, D.M. dos; TABOSA, J.N.; MICHEREFF FILHO, M.; LIRA, M.A.; BONFIM, M.H.; SOUZA, E.M. de; SAMPAIO, G.V.; BRITO, A.R. de M.B.; DOURADO, V.V.; TAVARES, J.Á.; NASCIMENTO NETO, J.G. do; NASCIMENTO NETO, J.G. do; TAVARES-FILHO, J.J.; ANDRADE-JÚNIOR, A.S.; CARVALHO, B.C. Caatingueiro: uma variedade de milho para o semi-árido nordestino. Aracaju:
Embrapa Tabuleiros Costeiros, 2004. (Embrapa Tabuleiros Costeiros. Comunicado técnico, 29).

COMPANHIA NACIONAL DE ABASTECIMENTO. Acompanhamento da safra brasileira - grãos - safras 2011/2012 - décimo primeiro levantamento - agosto 2012. Brasília: Conab, 2012. 29p.

COMPANHIA NACIONAL DE ABASTECIMENTO. Produção de milho no Ceará. 2013. Disponível em: <http://www.conab.gov. br/OlalaCMS/uploads/arquivos/12_04_03_10_47_52_milho_em graos_-_safra_2012___ceara.pdf>. Acesso em: 14 nov. 2013.

DING, S.; SU, P. Effects of tree shading on maize crop within a Poplar-maize compound system in Hexi Corridor oasis, northwestern China. Agroforestry Systems, v.80, p.117-129, 2010. DOI: $10.1007 / \mathrm{s} 10457-010-9287-\mathrm{x}$.

FOYER, C.H.; VANACKER, H.; GOMEZ, L.D.; HARBINSON, $\mathrm{J}$. Regulation of photosynthesis and antioxidant metabolism in maize leaves at optimal and chilling temperatures: review. Plant Physiology and Biochemistry, v.40, p.659-668, 2002. DOI: 10.1016/S0981-9428(02)01425-0.

FUENTES, J.D.; KING, K.M. Leaf photosynthesis and leaf conductance of maize grown hydroponically and in soil under field conditions. Agricultural and Forest Meteorology, v.45, p.155-166, 1989. DOI: 10.1016/0168-1923(89)90040-3.

HEINEMAN, A.M.; OTIENO, H.J.O.; MENGICH, E.K.; AMADALO, B.A. Growth and yield of eight agroforestry tree species in line plantings in Western Kenya and their effect on maize yields and soil properties. Forest Ecology and Management, v.91, p.103-135, 1997. DOI: 10.1016/S0378-1127(96)03885-6.

JACKSON, N.A.; WALLACE, J.S.; ONG, C.K. Tree pruning as a means of controlling water use in an agroforestry system in Kenya. Forest Ecology and Management, v.126, p.133-148, 2000. DOI: 10.1016/S0378-1127(99)00096-1.

JACKSON, P.C.; CAVELIER, J.; GOLDSTEIN, G.; MEINZER, F.C.; HOLBROOK, N.M. Partitioning of water resources among plants of a lowland tropical forest. Oecologia, v.101, p.197-203, 1995.

KANG, H.; SHANNON, D.A.; PRIOR, S.A.; ARRIAGA, F.J. Hedgerow pruning effects on light interception, water relations and yield in alley-cropped maize. Journal of Sustainable Agriculture, v.31, p.115-137, 2008. DOI: 10.1300/J064v31n04_08.

KHO, R.M. A general tree-environment-crop interaction equation for predictive understanding of agroforestry systems. Agriculture, Ecosystems and Environment, v.80, p.87-100, 2000. DOI: 10.1016/S0167-8809(00)00136-5.

KIM, S.-H.; GITZ, D.C.; SICHER, R.C.; BAKER, J.T.; TIMLIN, D.J.; REDDY, V.R. Temperature dependence of growth, development, and photosynthesis in maize under elevated $\mathrm{CO}_{2}$. Environmental and Experimental Botany, v.61, p.224-236, 2007. DOI: 10.1016/j.envexpbot.2007.06.005.

LARCHER, W. Ecofisiologia vegetal. São Carlos: RiMa, 2006. 550p.

LEMENIH, M.; GIDYELEW, T.; TEKETAY, D. Effects of canopy cover and understory environment of tree plantations on richness, density and size of colonizing woody species in 
southern Ethiopia. Forest Ecology and Management, v.194, p.1-10, 2004. DOI: 10.1016/j.foreco.2004.01.050.

LOTT, J.E.; KHAN, A.A.H.; BLACK, C.R.; ONG, C.K. Water use in a Grevillea robusta-maize overstorey agroforestry system in semi-arid Kenya. Forest Ecology and Management, v.180, p.45-59, 2003. DOI: 10.1016/S0378-1127(02)00603-5.

MAIA, S.M.F.; XAVIER, F.A.S.; OLIVEIRA, T.S.; MENDONÇA, E.S.; ARAÚJO FILHO, J.A. Organic carbon pools in a Luvisol under agroforestry and conventional farming systems in the semiarid region of Ceará, Brazil. Agroforestry Systems, v.71, p.127138, 2007. DOI: 10.1007/s10457-007-9063-8.

MAIA, S.M.F.; XAVIER, F.A. da S.; OLIVEIRA, T.S. de; MENDONÇA, E. de S.; ARAÚJO-FILHO, J.A. Frações de nitrogênio em Luvissolo sob sistemas agroflorestais e convencional no semiárido cearense. Revista Brasileira de Ciência do Solo, v.32, p.381-392, 2008. DOI: 10.1590/S0100-06832008000100036.

MATHUVA, M.N.; RAO, M.R.; SMITHSON, P.C.; COE, R. Improving maize (Zea mays) yields in semiarid highlands of Kenya: agroforestry or inorganic fertilizers? Field Crops Research, v.55, p.57-72, 1998. DOI: 10.1016/S0378-4290(97)00067-1.

MOLUA, E.L. The economics of tropical agroforestry systems: the case of agroforestry farms in Cameroon. Forest Policy and Economics, v.7, p.199-211, 2005. DOI: 10.1016/S13899341(03)00032-7.

MOURA, M.S.B. de; SOUZA, L.S.B. de; SILVA, T.G.F. da; SOARES, J.M.; CARMO, J.F.A. do; BRANDÃO, E.O. Modelos de crescimento para o feijão-caupi e o milho sob sistemas de plantio exclusivo e consorciado no semiárido brasileiro. Revista Brasileira de Agrometeorologia, v.16, p.275-284, 2008.

MUTHURI, C.W.; ONG, C.K.; BLACK, C.R.; NGUMI, V.W.; MATI, B.M. Tree and crop productivity in Grevillea, Alnus and Paulownia-based agroforestry systems in semi-arid Kenya. Forest Ecology and Management, v.212, p.23-39, 2005. DOI: 10.1016/j. foreco.2005.02.059.

OGOL, C.K.P.O.; SPENCE, J.R.; KEDDIE, A. Maize stem borer colonization, establishment and crop damage levels in a maize-leucaena agroforestry system in Kenya. Agriculture, Ecosystems and Environment, v.76, p.1-15, 1999. DOI: 10.1016/ S0167-8809(99)00077-8.

PACIULLO,D.S.; GOMIDE, C.A.; CASTRO, C.R.;FERNANDES, P.B.; MÜLLER, M.D.; PIRES, M.F.; FERNANDES, E.N.; XAVIER, D.F. Características produtivas e nutricionais do pasto em sistema agrossilvipastoril, conforme a distância das árvores. Pesquisa Agropecuária Brasileira, v.46, p.1173-1186, 2011. DOI: 10.1590/S0100-204X2011001000009.

PAIVA, A.S.; FERNANDES, E.J.; RODRIGUES, T.J.D.; TURCO, J.E.P. Condutância estomática em folhas de feijoeiro submetido a diferentes irrigações. Engenharia Agrícola, v.25, p.161-169, 2005. DOI: $10.1590 / \mathrm{S} 0100-69162005000100018$.

PÉREZ-MARIN, A.M.; MENEZES, R.S.C.; SILVA, E.D.; SAMPAIO, E.V. de S.B. Efeito da Gliricidia sepium sobre nutrientes do solo, microclima e produtividade do milho em sistema agroflorestal no Agreste Paraibano. Revista Brasileira de Ciência do Solo, v.30, p.555-564, 2006. DOI: 10.1590/S010006832006000300015.

RADERSMA, S.; ONG, C.K. Spatial distribution of root length density and soil water of linear agroforestry systems in sub-humid Kenya: implications for agroforestry models. Forest Ecology and Management, v.188, p.77-89, 2004. DOI: 10.1016/j. foreco.2003.07.021.

REGO, G.M.; POSSAMAI, E. Efeito do sombreamento sobre o teor de clorofila e crescimento inicial do Jequitibá-rosa. Boletim de Pesquisa Florestal, n.53, p.179-194, 2006.

REYNOLDS, P.E.; SIMPSON, J.A.; THEVATHASAN, N.V.; ANDREW, M.G. Effects of tree competition on corn and soybean photosynthesis, growth, and yield in a temperate tree-based agroforestry intercropping system in Southern Ontario, Canada. Ecological Engineering, v.29, p.362-371, 2007. DOI: 10.1016/j. ecoleng.2006.09.024.

SCHROTH, G.; D'ANGELO, S.A.; TEIXEIRA, W.G.; HAAG, D.; LIEBEREI, R. Conversion of secondary forest into agroforestry and monoculture plantations in Amazonia: consequences for biomass, litter and soil carbon stocks after 7 years. Forest Ecology and Management, v.163, p.131-150, 2002. DOI: 10.1016/S03781127(01)00537-0.

SEKIYA, N.; YANO, K. Water acquisition from rainfall and groundwater by legume crops developing deep rooting systems determined with stable isotope compositions of xylem waters. Field Crops Research, v.78, p.133-139, 2002. DOI: 10.1016/ S0378-4290(02)00120-X.

SOUZA, H.N. de; GOEDE, R.G.M. de; BRUSSAARD, L.; CARDOSO, I.M.; DUARTE, E.M.G.; FERNANDES, R.B.A.; GOMES, L.C.; PULLEMAN, M.M. Protective shade, tree diversity and soil properties in coffee agroforestry systems in the Atlantic Rainforest biome. Agriculture, Ecosystems and Environment, v.146, p.179-196, 2012. DOI: 10.1016/j.agee.2011.11.007.

WANG, Y.; ZHANG, B.; LIN, L.; ZEPP, H. Agroforestry system reduces subsurface lateral flow and nitrate loss in Jiangxi Province, China. Agriculture, Ecosystems and Environment, v.140, p.441-453, 2011. DOI: 10.1016/j.agee.2011.01.007.

YANG, L.; LIU, N.; REN, H.; WANG, J. Facilitation by two exotic Acacia: Acacia auriculiformis and Acacia mangium as nurse plants in South China. Forest Ecology and Management, v.257, p.1786-1793, 2009. DOI: 10.1016/j.foreco.2009.01.033.

Recebido em 4 de junho de 2012 e aprovado em 30 de outubro de 2012 